\title{
DAMPAK KONFLIK DAN RESOLUSI KONFLIK TERHADAP SISTEM PENDIDIKAN AGAMA ISLAM DI SEKOLAH SONGSERM ISLAM SEKSA PATANI, THAILAND SELATAN
}

\author{
Komareeyah Sulong dan Imam Machali \\ Sekolah Songserm Islam Seksa (SSIS) Pattani Thailand \\ Email: komareeyah.sulong@gmail.com
}

\begin{abstract}
Abstrak
Penelitian ini memaparkan tentang konflik dan resolusi konflik serta dampaknya terhadap sistem Pendidikan Agama Islam di Sekolah Songserm Islam Seksa Patani (SSIS) Thailand Selatan. Pembahasan difokuskan pada tiga persoalan. Pertama, bagaimana konflik dan resolusi konflik. Kedua, bagaimana dampak konflik terhadap sistem pendidikan agama Islam. Dan ketiga, bagaimana dampak resolusi konflik terhadap sistem pendidikan agama Islam. Hasil penelitian menunjukkan bahwa konflik di Pattani disebabkan beberapa faktor yaitu ketidakadilan, diskriminasi, saling tidak mempercayai, perbedaan kebudayaan, propaganda media, konflik politik dan kepentingan. Dampak konflik terhadap sistem pendidikan di SSIS adalah berkurangnya jam belajar, menurunnya prestasi belajar siswa dan kinerja guru, tidak menentunya sistem pendidikan yang disebabkan berubahnya kebijakan pemerintah dalam resolusi konflik, dan sekolah harus libur secara mendadak ketika terjadi konflik. Sedangkan dampak resolusi konflik terhadap Sistem Pendidikan Agama Islam di SSIS adalah meningkatnya kualitas kinerja guru, tumbuhnya semangat pendidik dalam proses pembelajaran, dan terbentuknya budaya belajar yang efektif dan kondusif di SSIS.
\end{abstract}

This study describes the conflict and its resolution as well as the impact on the system of Islamic Education in Schools Songserm Seksa Islam Patani (SSIS) South Thailand. The discussion focused on three issues. First, how the conflict and its resolution is. Second, how the impacts of the conflict on the education system of the Islamic religion. And third, how the impacts of conflict resolution on the 
Islamic education system. The results showed that the conflict in Pattani is due to several factors: injustice, discrimination, mistrust each other, the differences of culture, media propaganda, political conflicts and interests. The impact of conflict on the education system in SSIS is the reduction of school hours, the decline of student achievement and teacher performance, the uncertainty caused by the changes of government's policy on conflict resolution, and the school should be off abruptly during the conflict. While the impact of the conflict resolution toward Islamic Education System in SSIS is the increased quality of teacher performance, the growth of the spirit of educators in the learning process, and a culture of effective and conducive learning in SSIS.

Keywords: conflict, resolution, education, Islamic

\section{Pendahuluan}

Thailand (Muangthai) adalah salah satu negara anggota Association of South East Asian Nations (ASEAN). Pemerintahnya berbentuk kerajaan yang terdiri dari 77 propinsi dengan jumlah penduduk 75 juta jiwa. Wilayah Thailand bagian selatan banyak dihuni oleh umat Islam. Mereka terkonsentrasi di empat propinsi yaitu Yala, Natarhiwats, Pattani dan Setun. Di empat propinsi ini 80 $\%$ penduduknya beragama Islam.

Pada awal sejarahnya, di Thailand bagian Selatan terdapat sebuah kerajaan yang makmur dan berpengaruh di Asia Tenggara, kerajaan tersebut adalah Kerajaan Patani. Namun seiring dengan terjadinya krisis politik pada akhir abad XVII, negeri Patani mengalami perpecahan dan distabilitas ekonomi politik. Dalam kedaan seperti itu, orang-orang Siam mendapat kesempatan besar untuk menyerangnya, menguasai dan mengambil alih kekuasaan Patani pada tahun 1785. Penguasaan orang-orang Siam terhadap Patani inilah yang menjadi akar perpecahan dan konflik yang berkepanjangan di Thailand sampai saat ini. Upaya integrasi Negeri Patani ke dalam sistem politik Thailand telah banyak dilakukan dan tidak sedikit mengalami kebuntuan dan banyak protes. Sistem politik pemerintahan Thailand berupa "Divide and Rule" pada tahun 1816 berakibat pada pecahnya negeri Patani terpecah-pecah menjadi tujuh negeri kecil, yaitu Patani, Nongcik, Jamu, Jalor, Teluban, Lengeh, dan Raman. Masing-masing negeri dipimpin oleh seorang raja (Ibrahim, tt: 130).

Bersama dengan berkembangannya kolonialisme Inggris ke Asia, terjadi persaingan antara Inggris dengan Thai untuk menguasai Semenanjung Malayu. Pada tahun 1832 M, Thai dapat menaklukkan Patani (Ali, 2005: 200). Berdasarkan undang-undang Thesaphiban 1902 dan Traktat Anglo-Siam 1909, Thai harus melepaskan klaim kekuasaannya atas empat Negara Malaya 
yang pada waktu itu dimasukkan dalam Malaya-Inggris. Sebagai gantinya, Thai mendapatkan pengakuan secara diam-diam atas kekuasaannya terhadap wilayah dan orang-orang Melayu di sebelah selatan-Patani, Yala, Satun, dan Narathiwat (Pitsuwan, 1989: 108).

Pada tahun 1906 pemerintah Thai menerapkan sistem yang dikenal dengan boriwen cit hua muang (wilayah sentral). Dalam sistem tersebut yang dijadikan tujuh negeri kecil hanya satu negeri, yaitu Monton Patani (Kota Besar Patani). Kemudian dibagi lagi menjadi empat negeri, yaitu Patani, Yala, Narathiwat, dan Saiburi, yang pada setiap negeri dikepalai oleh seorang gubernur. Pada tahun 1931, Negeri Saiburi (Taluban) diintegrasikan ke dalam Negeri Patani, dan Satun ketika itu masuk ke dalam Monton Kedah (Propinsi Kedah). Pada tahun 1936, istilah negeri dihapus dan diganti dengan istilah Changwad yang dalam bahasa Melayu berarti propinsi atau wilayah sebagaimana dipakai sekarang. Setelah kesultanan Patani jatuh ke tengah orang Budha secara total pada tahun 1902, kaum Muslim di daerah itu terisolasir dari birokrasi negera karena perbedaan agama, bahasa, dan budaya. Mereka dipandang sebagai problem oleh Pemerintah Thailand (Saiful, 1993: 325). Daerah ini dipandang sebagai daerah kelabu, di mana dua budaya yang berbeda yang berorientasi pada Islam dan Budha terjadi tumpang tindih. Secara kultural kaum Muslim dekat dengan dunia Melayu, dan secara politis mereka bagian dari Thailand yang agama dan negaranya beragama Budha (Siripachana, 1975: 47).

Sejak dilaksanakan program-program pembaharuan oleh pemerintah Thailand kepada masyarakat Patani, hal ini berdampak pada timbulnya sikap sentimen etnis, kultural, dan agama di kalangan Muslim-Melayu. Mereka tidak ingin diatur oleh Pemerintah Bangkok, dan berusaha kembali memiliki hak otonomi seperti semula, terutama dalam bidang budaya, agama, dan hukum. Hal-hal inilah yang menjadi benih konflik dan perpecahan sejak tahun 1903 hingga saat ini.

Pada tahun 1966 M pemerintah Thailand melalui Undang-undang kependidikan mewajibkan kepada setiap institusi pendidikan keagamaan dan pondok untuk mendaftarkan secara resmi kepada pemerintah di bawah akta Rong Rian Rasd Sorn Islam (sekolah Swasta Pendidikan Agama Islam). sejak itulah, lembaga pendidikan keagamaan pondok di Patani mengalami perubahan menjadi lembaga pendidikan yang sistematik dan terpantau oleh Kementerian Kependidikan Nasional (Capakiya, 2002: 41). Pemerintah Muang Thai mendorong sistem sekolah agama swasta (madrasah) memasukkan kurikulum agama dan kurikulum umum dalam sistem pendidikan formal. 
Dengan langkah ini, di satu sisi madrasah (sistem pendidikan formal) menjadi semakin popular dan berkembang di masyarakat Melayu Patani di Muang Thai Selatan. Namun di sisi lain, pendidikan keagamaan dengan sistem pondok (non formal) lambat laun mulai terpinggirkan dan ditinggalkan oleh masyarakat (Madami, 2013: 70).

Penelitian ini memaparkan dampak resolusi konflik terhadap Sistem Pendidikan Agama Islam di Sekolah Songserm Islam Seksa Patani, Thailand Selatan. Diketahui bahwa konflik berkepanjangan yang terjadi di Patani sangat mempengaruhi sistem dan pola pendidikan di Patani. Upaya-upaya resolusi terus dilakukan oleh pemerintah Thailand. Namun demikian, resolusi konflik tersebut berdampak pada sistem pendidikan Agama Islam di lembaga-lembaga formal dan nonformal. Pembahasan difokuskan pada tiga persoalan yaitu pertama, bagaimana konflik dan resolusi konflik di Patani, kedua, bagaimana dampak konflik terhadap sistem pendidikan agama Islam, dan ketiga, bagaimana dampak resolusi konflik terhadap sistem pendidikan agama Islam. Kajian difokuskan di Sekolah Songserm Islam Seksa (SSIS) yang terletak di wilayah Pattani Thailand Selatan.

Pada awalnya sekolah "Nahdlatu As Subban" atau sekolah Songserm Islam Seksa lebih dikenal dengan nama "Pondok Pekalan Jambu" yang didirikan oleh To'guru Kyai H. Ismail bin Abdul Hamid. Pada awalnya pondok ini mengajarkan al Quran dan kitab-kitab klasik di masjid dengan cara yang sederhana, namun pada perkembangannya sampai saat ini sekolah ini mengajarkan pendidikan agama dan umum yang dilakukan dalam satu atap dengan sistem administrasi yang berbeda. Hal ini tidak lepas dari pengaruh resolusi konflik yang dilakukan oleh pemerintah Thailand terhadap masyarakat Patani.

\section{Metode Penelitian}

Penelitian ini merupakan penelitian kualitatif dengan studi kasus di Sekolah Songserm Islam Seksa Patani, Thailand Selatan. Pengumpulan data dilakukan dengan tiga teknik yaitu wawancara, observasi dan dokumentasi.

Pertama, wawancara dilakukan kepada para stakeholders sekolah meliputi kepala sekolah, guru agama, siswa, dan masyarakat di lingkungan sekolah tentang bagaimana dampak resolusi konflik sektarian terhadap sistem pendidikan agama Islam. Kedua, observasi dilakukan dengan cara mengamati seluruh aktifitas di Sekolah Songserm Islam Seksa Patani, Thailand Selatan, dan ketiga, dokumentasi dengan cara mengumpulkan berbagai dokumen terkait dengan konflik dan resolusi konflik serta dampaknya terhadap sistem 
pendidikan agama Islam di Sekolah Songserm Islam Seksa Patani, Thailand Selatan.

Uji keabsahan data menggunakan teknik trianggulasi sumber, yaitu mendapatkan data dari sumber yang berbeda-beda dengan teknik yang sama. Metode analisis data menggunakan model Miles and Hubermany ang meliputi, pengumpulan data, display data, reduksi, dan penyimpulan.

\section{Pembahasan}

\section{Konflik dan Resolusi Konflik di Patani, Thailand Selatan}

a. Konflik di Patani, Thailand Selatan

Sejarah konflik di Patani berawal dari perebutan wilayah dan kekuasaan antara Inggris dan Thai pada masa kolonialisme. Mereka bersaing untuk menguasai Semenanjung Malayu, dan pada tahun 1832 M, Thai dapat menaklukan Patani. Berdasarkan undang-undang Thesaphiban 1902 dan traktar Anglo-Siam 1909, Thai harus melepaskan klaim kekuasaannya atas empat Negara bagian Malaya yang pada waktu itu dimasukan dalam MalayaInggris. Sebagai gantinya, Thai mendapatkan pengakuan secara diam-diam atas kekuasaannya terhadap wilayah dan orang-orang Melayu di sebelah Selatan (Patani, Yala, Satun dan Narathiwat). Pada tahun 1906 pemerintah Thai menerapkan sistem yang dikenal dengan boriwen cit hua muang (wilayah sentral). Dalam sistem itu yang dijadikan tujuh negeri kecil hanya satu negeri, yaitu Monton Patani (Kota Besar Patani). Kemudian dibagi lagi menjadi empat negeri, yaitu Patani, Yala, Narathiwat dan Saiburi, yang pada setiap negeri dipimpin oleh seorang gubenur (Pitsuwan,1989: 108).

Setelah kesultanan Patani jatuh ke tangan orang Budha pada tahun 1902, kaum muslim Patani terisolasir dari birokrasi negara karena perbedaan agama, bahasa dan budaya. Kaum muslim Patani dipandang sebagai problem oleh pemerintah Thailand, dan daerah Patani dipandang sebagai daerah "kelabu" yaitu daerah yang memiliki dua budaya berbeda dan tumpang tindih. Di satu sisi, secara budaya dan agama mereka adalah orang muslim-melayu beragama Islam, dan di sisi lain, secara politis mereka adalah bagian dari negara Thailand yang agama dan negaranya adalah Budha (Muzani, 1993: 325).

Semenjak dilaksanakan program-program pembaruan oleh pemerintah Thailand, maka timbul sentiment-sentiment etnis, budaya dan agama di kalangan muslim Melayu-Patani, sehingga mendorong reaksi, resistensi, dan solidaritas sesama muslim-Melayu untuk melakukan perlawanan terhadap pemerintah. Tujuan yang diperjuangkan adalah kembalinya otonomi 
kekuasaan, budaya, agama dan hukum. Hal inilah yang menjadi tuntutan dan perjuangan masyarakat muslim-Patani sejak tahun 1903 hingga sekarang (Hasbullah, 2003: 266).

Dalam perjuangan dan perlawannnya mewujudkan otonominya, umat muslim Patani membentuk organisasi bernama Gabungan Melayu Patani Raya (GEMPAR), didirikan di negeri Kelantan, Malaysia pada 5 Maret 1948 M., dipimpin oleh Muhammad Mahayyiddin. Organisasi ini tersebar luas ke negeri Kedah, Pinang dan Singapura (Nurdi, 2010: 81). Tujuan utama GEMPAR ini adalah (1) mempersatukan seluruh orang Melayu dan keturunannya di Muang Thai Selatan, (2) membangun hubungan yang lebih dekat dengan penduduk-penduduk di wilayah Muang Thai Selatan serta memperbaiki standar kehidupan mereka, dan (3) saling membantu dan bekejasama, memperbaiki pendidikan dan menghidupkan kembali kebudayaan Melayu di wilayah Muang Thai Selatan (Madami, 2013: 146).

Selain organiasi GEMPAR tersebut, pada tahun 1980-an muncul juga organisasi pergerakan perjuangan yang beroreintasi kemerdekaan patani seperti Patani United Liberation (PULO), Barisan Nasional Pembebasan Patani (BNPP), dan Barisan Revolusi Nasional (BRN). Selain itu juga muncul gerakan Jama'ah Dakwah Tabligh, gerakan fundamentalis (dikenal dengan gerakan Wahabi atau kaum muda), gerakan pelajar, umumnya gerakan-gerakan tersebut membawa simbol keagamaan, kebangsaan dan kebudayaan sebagai asas dan tujuan utama (Madami, 2013: 147).

Gerakan-gerakan perjuangan di Patani lebih bertujuan ke arah kemerdekaan Patani. Keinginan mereka untuk menegakkan panji-panji Islam di Patani bertujuan sebagai berikut (1) menumbuhkan daulat Islamiah Patani Darussalam berlandasan hukum al Quran, sunah Rasulullah dan ijtihad para ulama salafus shaleh. (2) Meningkatkan perkembangan agama Islam dengan berlandaskan identitas budaya dan bangsa Melayu. (3) memberi dukungan gagasan dan prinsip perpaduan dan persatuan Negara-negara Islam yang didukung oleh Persidangan Negara-negara Islam (OIC) (Malik, 1994: 268).

Pola pikir dan pemahaman tentang dar alislami (negara Islam), dan dar al-harbi (wilayah perang) ikut membentuk kesadaran masyarakat Patani dalam bergerak memperjuangkan kemerdekaannya. Bagi masyarakat Melayu Patani sebagai bangsa, mereka merasa telah dikuasai dan dijajah oleh bangsa lain (Thailand), oleh karenanya sepanjang masih tertanam kesadaran dan pemahaman penjajahan (koloni) terhadap masyarakat Patani, maka perlawanan untuk mewujudkan kemerdekaan tidak akan pernah berhenti di Muang Thai, 
dan itu terbukti hingga saat ini meski upaya-upaya resolusi telah dilakukan (Madami, 2013: 148).

Penelitian yang dilakukan oleh College of Islamic Studies, Prince of Songkla University berjudul "The Attitudes of the People toward Unpeace in the Three Southern Border Provinces of Thailand" menyebutkan faktor-faktor penyebab konflik di daerah Patani yaitu (http://soreda.oas.psu.ac.th):

1. Mayoritas masyarakat berpendapat bahwa munculnya konflik disebabkan oleh ketidakadilan, saling tidak mempercayai, perbedaan kebudayaan, propaganda media, konflik politik, keinginan masyarakat untuk dapat diakui oleh pemerintah.

2. Mayoritas masyarakat memiliki sikap dan pendapat yang berbeda-beda terhadap sebab munculnya konflik.

3. Masyarakat memiliki sikap terhadap kasus kebakaran sekolah dan sejumlah guru yang menjadi korban karena telah mengkhianati kebudayaan orang Thai Muslim (orang Muslim Melayu). Pada hal ini masyarakat masih raguragu dan setiap pendapat memiliki sikap yang berbeda.

4. Masyarakat memiliki sikap terhadap kelompok militan (Gerakan Melayu), yang meminta pajak kepada orang kaya yang non-muslim. Pada hal ini masyarakat masih ragu-ragu dan mayoritas masyarakat memiliki sikap yang sama.

5. Masyarakat memiliki sikap terhadap kasus bom jembatan, rel kereta api dan kantor pegawai Negara, karena melawan pemerintah yang tidak memberikan keadilan serta menghina dan mendzalimi orang Thai Muslim (orang muslim Melayu). Padahal ini masyarakat setuju dan memiliki sikap yang sama.

6. Masyarakat memiliki sikap terhadap masyarakat yang tidak bisa melaksanakan kegiatan dan pekerjaan pada hari jum'at karena akan dipotong kuping. Dalam hal ini masyarakat setuju dan memiliki sikap yang sama.

7. Masyarakat memiliki sikap terhadap masyarakat yang melarikan diri dari konflik karena merasa tidak nyaman baik bagi dirinya sendiri dan bagi harta benda. Dalam hal ini masyarakat setuju dan memiliki sikap yang sama.

8. Masyarakat memiliki sikap terhadap sekolah yang selalu sering libur dengan cara mendadak, yang akan membuat siswa tidak mendapatkan pendidikan yang maksimal. Dalam hal ini masyarakat tidak setuju dan mayoritas masyarakat memiliki sikap berbeda-beda.

9. Masyarakat memiliki sikap terhadap masyarakat yang tidak bisa melaksanakan 
kegiatan/kerja pada waktu malam karena merasa tidak aman. Dalam hal ini masyarakat setuju dan mayoritas masyarakat memiliki sikap yang sama.

10. Masyarakat memiliki sikap terhadap sekelompok orang yang memberikan uang jaminan atau perlindungan kepada kelompok militan (Gerakan Melayu) karena dapat memberi keselamatan lebih dari pada penerintah. Dalam hal ini masyarakat setuju dan mayoritas masyarakat memiliki sikap yang sama.

11. Masyarakat memiliki sikap terhadap tentara, polisi yang menjadi korban karena menjadi pihak yang selalu menghina dan mendzolimi terhadap orang Thai muslim (orang muslim Melayu). Dalam hal ini masyarakat setuju dan mayoritas masyarakat memiliki sikap yang sama.

12. Masyarakat memiliki sikap terhadap masyarakat yang tidak bersalah tetapi menjadi korban karena ingin menekan dan melawan kekuasaan pemerintah. Dalam hal ini masyarakat setuju dan mayoritas masyarakat memiliki sikap yang sama.

b. Resolusi Konflik di Patani, Thailand Selatan

Damai secara sederhana dapat dimaknai sebagai tidak adanya perang atau konflik dan kekerasan. Faktor penyebab terjadinya suasana damai adalah ketika individu memiliki rasa kedamaian dalam diri sendiri, memiliki kemampuan untuk mengontrol emosi dan pikirannya agar tidak melakukan tindakan yang merugikan orang lain serta bisa memicu terjadinya konflik dan kekerasan. Perdamaian adalah konsep dan cara pandang yang positif baik terhadap dirinya maupun kepada orang lain (Machali, 2013: 43).

Perdamaian dapat didefinisikan dalam dua sisi, pertama damai yang "negatif", yang tidak adanya perang atau konflik kekerasan. Situasi ini dicapai dengan pendekatan struktural, yaitu pencegahan setiap potensi konflik dengan cara mengontrol pihak-pihak yang bisa menyulut potensi konflik menjadi konflik terbuka dan menggunakan kekerasan. Kedua, damai yang "positif", yaitu suasana yang sejahtera, adanya kebebasan dan keadilan yang menjadi dasar terciptanya suasana damai dalam suatu komunitas.

Ursula Franklin berpendapat bahwa damai bukan hanya sekedar tidak adanya perang, tetapi damai juga terciptanya keadilan dan hilangnya ketakutan dalam diri individu dan masyarakat. Ketakutan yang dimaksud adalah rasa tidak aman dari faktor ekonomi seperti takut tidak punya pekerjaan atau tempat tinggal yang layak. Franklin lebih jauh menoroti pada apa yang disebut "sistem yang mengancam", yaitu sistem yang diciptakan oleh suatu kelompok 
untuk mengontrol dan mengatur individu atau kelompok lain dengan member mereka rasa takut dan ketidakpastian demi mencapai tujuan tertentu. Dengan kata lain, untuk menciptakan perdamaian ataupun kehidupan yang damai harus dilakukan upaya untuk memenuhi rasa keadilan dan rasa aman individu atau komunitas, baik aman dari ancaman fisik, ekonomi ataupun ancaman dari aspek lainnya. Selain itu, para ahli dan praktisi conflict resolution (resolusi konflik) memahami damai bukan hanya bebas dari peperangan (absence of war) tapi mencakup adanya keadilan ekonomi, sosial dan budaya, serta bebas dari diskriminasi ras, kelas, jenis kelamin, dan agama (Machali, 2013: 43-44).

Upaya melakukan Resolusi Konflik di Patani terus dilakukan, beberapa kebijakan strategis di dilakukan oleh pemerintah Thailand. Diantaranya adalah program pengembangan propinsi Thailand Selatan (Patani) pada tahun 2012-2014. Program ini berisi sembilan program strategis yaitu (http:// bangkokbiznews.com):

1. Mengembangkan administrasi dengan melibatkan pemerintah dan masyarakat dalam mengatasi masalah di wilayah konflik.

2. Membangkitkan semangat warga masyarakat dalam berpartisipasi untuk menciptakan kedamaian.

3. Menciptakan kondisi dan situasi untuk mencari solusi konflik dengan jalan perdamaian.

4. Meningkatkan pendidikan agama, bahasa, seni, multikultural, kebudayaan dan sejarah daerah.

5. Menjunjung tinggi Hak Asasi Manusia (HAM) untuk memberikan keadilan, menegakan hukum, serta menggunakan ajaran agama atau keadilan dalam masyarakat, untuk mengatasi konflik, pemulihan dan pengembalian bagi masyarakat yang terkena dampak konflik.

6. Membangun kepercayaan dan meningkatkan efektifitas dalam mengembangkan perekonomian sesuai dengan kemampuan hidup dan kebutuhan masyarakat.

7. Meningkatkan kualitas hidup masyarakat serta memberi kesempatan kepada masyarakat yang kurang mampu.

8. Komunikasi untuk menciptakan pemahaman yang baik.

9. Menjalin kerja sama dengan Negara lain dan mempersiapkan untuk menjadi anggota Association of South East Asian Nations (ASEAN).

Selain hal tersebut, masyarakat Patani menawarkan beberapa solusi dalam mengatasi konflik yang terjadi di Thailand. Solusi tersebut dirumuskan 
dalam butir-butir resolusi konflik sebagai berikut:

1. Pemerintah harus menjalin hubungan yang baik dengan pegawai negeri untuk memberi pemahaman tentang kebudayaan agar mereka tidak berpikir negatif terhadap masyarakat (orang muslim Melayu).

2. Pemerintah harus memberi kesempatan bagi masyarakat setempat untuk menjadi pegawai negeri sebanyak mungkin.

3. Pemerintah tidak perlu mengirim pegawai negeri yang berbuat menyimpang untuk bekerja di Patani.

4. Pemerintah tidak perlu mengunakan kekerasan dalam mengatasi masalah.

5. Pemerintah harus menyediakan informasi disetiap cabang seperti lembanga Southern Border Provinces Administration Centre (SBPAC)

6. Pemerintah harus memberikan beasiswa kepada para remaja untuk mendapatkan pendidikan sesuai dengan jurusan yang mereka inginkan.

7. Pemerintah menjadikan ajaran Islam sebagai solusi dalam mengatasi permasalahan.

8. Pemerintah harus berpikir positif terhadap Pondok (Pesantren) dan To'guru (Kiyai).

9. Pemerintah harus menghapuskan kaum tertindas

10. Pemerintah harus memberikan otonomi yang luas kepada Thailand Selatan (Patani, Narathiwat, Yala).

Proses terjadinya konflik dan upaya resolusi konflik yang dilakukan di Thailand Selatan (Patani) samapai pada tahun 2004 dapat di ringkas dalam tabel berikut:

Tabel 1. Konflik dan Resolusi Konflik

\begin{tabular}{cccc}
\hline No & \multicolumn{1}{c}{ Konflik di Patani } & No & Resolusi Konflik di Patani \\
\hline 1. & $\begin{array}{l}\text { Pada tahun 1785 M. Siam berhasil } \\
\text { menaklukkan dan menguasai Patani. Sejak }\end{array}$ & 1. & Pada tahun 1981 M. Pemerintah \\
jatuhnya sistem pemerintahan Kesultanan & & membangunkan sebuah lembaga \\
Islam Melayu Patani mulai muncul gerakan- & konflik di Thailand Selatan. \\
gerakan dalam memperjuangkan untuk & & Yang dimaksudkan adalah \\
mengembalikan hak-hak kedaulatan mereka. & lembaga Southern Border Provinces \\
Dari kelompok-kelompok perjuangan tanah & Administration Centre (SBPAC). Pada \\
Melayu Patani telah membentukan diri & masa itu pemerintah membagi \\
menjadi sebuah gerakan yang tersembunyi & 2 bagian yakni dalam bidang \\
yang dinamai dengan Gabungan Melayu & pembangunan dan keamanan. \\
Patani Raya (GEMPAR). &
\end{tabular}




\begin{tabular}{cc}
\hline No & \multicolumn{1}{c}{ Konflik di Patani } \\
\hline 2. & Mulai pada tahun 1980-an, dalam suasana \\
politik bebas di bawah sistem pemerintahan \\
demokrasi Muang Thai, di tengah-tengah \\
masyarakat Melayu Patani muncul pergerakan \\
perjuangan yang beroreintasi kepada agama \\
dan bangsa yang berperan secara aktif dan \\
terbuka. Lahirnya gerakan perjuangan \\
bersenjata untuk memisahkan diri, yang \\
tergabung dalam kelompok organisasi seperti \\
Patani United Liberation (PULO), Barisan \\
Nasional Pembebasan Patani (BNPP), Barisan \\
Revolusi Nasional (BRN). Di samping itu juga \\
muncul gerakan Jama'ah Dakwah Tabligh, \\
gerakan fundamentalis (dikenal dengan \\
gerakan Wahabi atau kaum muda), gerakan \\
pelajar, secara umumnya gerakan-gerakan \\
tersebut membawa symbol keagamaan, \\
kebangsaan dan kebudayaan sebagai asas \\
dan tujuan utama.
\end{tabular}

3. Pada tanggal 4 Januari tahun $2004 \mathrm{M}$. ada kasus pencurian pistol militer di kabupaten Jo'irong Narathiwat dan pada tanggal 28 April tahun 2004 kasus kejadian penembakan antara gerakan Patani dan militer Negara Thailand yang berada di Patani di masjid Keresik Patani dan pada tanggal 25 Oktober tahun 2004 ada kasus kejadian pembubaran demo di kabupaten Takbai Narathiwat pada kasus tersebut penyebab 108 kubar yang meninggal. Dan sampai saat kini masyarakat di Patani masih berada didalam keadaan konflik.

\section{No Resolusi Konflik di Patani \\ 2. Sejak tahun 1996-2004 M. Southern \\ Border Provinces Administration Centre (SBPAC) selalu berubah dan sering kali diganti pemimpinnya dan kebijakannya juga terus berganti sesuai keinginan pemerintah.}

3. Pada tahun 2004 M. setelah ada kasus pencurian pistol militer di kabupaten Jo'irong Narathiwat dan kasus kejadian penembakan antara gerakan Patani dan militer Negara Thailand yang berada di Patani di masjid Keresik Patani dan kasus kejadian pembubaran demo di kabupaten Takbai Narathiwat pada kasus tersebut penyebab 108 kubar yang meninggal. Pemerintah memutuskan Southern Border Provinces Administration Centre (SBPAC) adalah pusat yang bekerjasama dengan beberapa pihak di daerah propinsi Thailand Selatan (Patani) untuk mencari solusi yang baik dan cocok bagi masyarakat, supaya masyarakat di Patani mendapatkan kedamaian dan kesejahteraan seperti yang diharapkan oleh pemerintah.

\section{Dampak Konflik terhadap Sistem Pendidikan Agama Islam di Sekolah Songserm Islam Seksa}

Konflik yang terjadi di Patani membawa dampak bagi kehidupan masyarakat baik internal maupun ekternal. Konflik juga membawa rasa tidak aman, damai, kepercayaan, kekompakan dan kesejahteraan. Dalam konteks Sekolah Songserm Islam Seksa (SSIS), konflik berdampak pada sistem pendidikan agama Islamyang terjadi. Dampak konflik terhadap sistem pendidikan agama Islam di Sekolah Songserm Islam Seksa adalah sebagai berikut:

Pertama, berkurangnya jam belajar. Konflik berdampak terhadap sistem pembelajaran yang berlangsung. Terjadi penembakan, pembakaran sekolah 
atau bom mengakibatkan lembaga pendidikan atau sekolah yang dekat dengan lokasi konflik harus dikurangi jam belajarnya, sehingga proses pembalajaran tidak dapat berjalan dengan maksimal. Akibat berkurangnya jam pembelajaran maka akan berpengaruh terhadap Prestasi siswa. Prestasi siswa menurun karena motivasi belajarnya menurun akibat terjadinya konflik.

Kedua, kinerja guru menurun. Guru di Patani tidak bisa beraktivitas seperti biasa, oleh karena sering terjadi kasus penembakan guru di sekolah agama Islam swasta. Hal ini sangat berdampak terhadap aktivitas dalam proses pembelajaran. Hal ini dapat dilihat dari tidak maksimalnya proses pembelajaran, rendahnya semangat guru dalam mengajar, dan kurangnya kesiapan guru dalam menyiapkan pembelajaran.

Ketiga, tidak menentunya sistem pendidikan sekolah yang dilaksanakan. Hal ini disebabkan oleh kebijakan yang berubah-ubah dalam rangka resolusi konflik. Kurikulum yang digunakan di sekolah agama Islam swasta adalah kurikulumyang diberikan oleh pemerintah yang meliputi mata pelajaran Saman (umum). Kurikulum ini memiliki 8 mata pelajaran yang wajib dibelajari yaitu Bahasa Thai, Matematika, Ilmu Sains (Ilmu Alam), Ilmu sosial dan kebudayaan, Kesehatan dan Olahraga, Kesenian, Dasar Kejuruan, dan Bahasa Asing. Selain itu juga menerapkan kurikulum Pendidikan Agama Islam Nasional yang meliputi mata pelajaran Agama. Pada kurikulum ini juga memiliki 8 mata pelajaran yang wajib dibelajari yaitu al Quran (Tafsir), Haditst, Fiqh, Aqidah, Sejarah, Akhlak, Bahasa Arab, dan Bahasa Melayu. Dengan kurikulum tersebut sekolah agama Islam swasta merasa keberatan, sebab beban mata pelajarannya terlalu banyak.

Keempat, tidak adanya kepastian hari efektif belajar dan libur sekolah. Hal ini disebabkan oleh konflik yang terjadi sewaktu-waktu, sehingga hari libur sekolah dapat terjadi sewaktu-waktu, bahkan dapat secara mendadak libur ketika terjadi konflik. Dalam kondisi konflik ini sering kali terjadi penembakan terhadap guru dan pengawai sekolah. Oleh karena itu, program sekolah tidak dapat berjalan secara maksimal.

Faktor penyebab terjadinya konflik di Patani lebih disebabkan oleh ketidakadilan yang dirasakan oleh masyarakat muslim Patani dari pihak pemerintah Thailand. Hal ini-dalam pandangan masyarakat Patani-bisa dilihat dari beberapa kebijakan yang diberikan diantaranya adalah, pertama, pemerintah berusaha untuk menghapuskan identitas orang-orang Melayu dengan mewajibkan penggunaan bahasa Thai dalam proses pembelajaran di kelas. Hal ini dalam proses panjang pelan-pelan akan berdampak pada menyingkirnya 
atau hilangnya bahasa Melayu yang menjadi identitas masyarakat Patani.

Kedua, dalam kebijakannya, pemerintah meng-"anaktirikan" sekolah TADIKA dalam memberikan bantuan dan dukungan baik dari segi sarana dan prasarana sekolah maupun fasilitas bagi guru TADIKA. Dengan kebijakan ini, sekolah TADIKA yang menjadi tempat belajar masyarakat muslim Patani menjadi tidak berdaya karena kurangnya dukungan pemerintah, sehingga berdampak pada kualitas dan mutu pendidikan. kemudian, lama-lama sekolah TADIKA semakin tertinggal dan tidak diminati oleh masyarakatnya.

Selain itu, diskriminasi terhadap masyarakat muslim Patani juga menjadi faktor penyebab konflik. Hal ini dapat dilihat dari sulitnya kesempatan mendapatkan posisi-posisi strategis di ruang-ruang publik, padahal 85\% masyarakat Patani beragama Islam. Pegawai-pegawi negeri, pemimpin-pemimpin propinsi dan pemimpin-pemimpin daerah di Patani sebagian besar di kuasai oleh orang-orang dari luar propinsi Patani dan bukan muslim

\section{Dampak Resolusi Konflik terhadap Sistem Pendidikan Agama Islam di Sekolah Songserm Islam Seksa}

Resolusi konflik yang terus dilakukan oleh pemerintah Thailand terhadap masyarakat Patani berpengaruh terhadap sistem pendidikan Agama Islam di Sekolah Songserm Islam Seksa. Dampak terhadap sistem pendidikan Agama Islam tersebut adalah sebagai berikut:

Pertama, meningkatkan kualitas kinerja guru dalam proses pembelajaran di sekolah agama Islam swasta. Upaya rekonsiliasi dan resolusi konflik membawa dampak pada kinerja guru. Suasana kondusif memacu lingkungan pendidikan yang efektif dalam pembelajaran. Program-program kegiatan kependidikan yang diberikan oleh pemerintah sebagai upaya rekonsiliasi juga berakibat kepada kondisifitas kegiatan pendidikan. Hal ini berakibat kepada meningkatnya kinerja guru terutama pada sekolah agama Islam swasta. Dampak turunannya adalah prestasi peserta didik meningkat.

Kedua, menumbuhan semangat pendidik dalam proses pembelajaran di sekolah agama Islam. Konflik yang terjadi selama ini menyebabkan trauman tersendiri bagi para guru, mereka merasa terancam dan tidak semangat dalam menunaikan tugasnya dalam mengajar. Rekonsiliasi yang dilakukan berdampak positif bagi proses pembelajaran. Guru merasa aman dan nyaman sehingga proses pembalajaran dapat berjalan dengan baik. Guru juga dapat dengan leluasa meningkatkan kompetensinya melalui berbagai program yang dibarikan oleh pemerintah. 
Ketiga, bagi peserta didik resolusi konflik berakibat pada semangat dan kondusifitas pembelajaran. Proses pembelajaran yang baik memerlukan lingkungan yang nyaman dan kondusif untuk pembelajaran. Resolusi konflik yang dilakukan oleh pemerintah Thailand terhadap masyarakat Patani dengan berbagai program yang dilakukan membentuk lingkungan yang lebih baik; aman, kondusif, damai, dan sejahtera. Dengan lingkungan yang demikian tersebut, maka proses pemelajaran menjadi efektif, dan peserta didik menjadi lebih semangat dan termotivasi dalam belajar.

Faktor pendukung upaya resolusi konflik ini diantaranya adalah pertama, tumbuhnya kepercayaan pemerintah terhadap masyarakat Patani. Kepercayaan menjadi faktor sangat penting dalam membangun hubungan yang harmonis, damai, aman, dan sejahtera antarmasyarakat dan masyarakat dengan pemerintah. Hal ini berbeda dengan sikap sebelumnya yang lebih mengedepankan sikap curiga pemeritah terhadap masyarakat muslim Patani. Kedua, kesediaan dan keihlasan menerima sejarah bagi masyarakat Pattani. Jika masyarakat muslim Patani masih berpandangan dan berkesadaran bahwa pemerintah Thailand adalah menjajah Patani, maka resolusi konflik yang berujung pada perdamaian, dan harmonisasi kehidupan tidak akan pernah terjadi. Oleh karena itu, keihlasan menerima sejarah masa lalu, dan merajut kehidupan dan membangun bersama adalah kunci resolusi konflik di Pattani. Hal ini sebagaimana disampaikan oleh salah seorang tokoh bahwa "masyarakat Patani mengetahui dan bersedia menerima sejarah Pattani masa lalu, kemudian menjadi pelajaran bagi kehidupan saat ini dan untuk hidup bersama dengan aman dan damai"(Mu'thajan, wawancara: 17 Agustus 2014) dan "Masyarakat di Patani harus mampu melupakan sejarah kelamnya demi masa depan" (Benjman, wawancara: 25 Agustus 2014).

\section{Simpulan}

Dari pemaparan di atas, simpulan yang dapat dipaparkan adalah bahwa munculnya konflik yang terjadi di patani lebih disebabkan oleh beberapa faktor diantaranya adalah ketidakadilan, diskriminasi, saling tidak mempercayai, perbedaan kebudayaan, propaganda media, konflik politik dan kepentingan. Konflik yang berkepanjangan dan dari generasi ke generasi tersebut mendorong upaya resolusi. Hal-hal yang dilakukan dalam rangka resolusi konflik ini adalah memberikan kesempatan dan hak yang sama bagi masyarakat Patani, 
pemerintah memberikan otonomi yang luas di daerah Thailand Selatan yang mayoritas penduduknya beragama Islam. Secara internal, masyarakat Patani mulai munculnya kesediaan dan keihlasan menerima sejarah masa lalu dan merangkai kehidupan yang lebih baik, bebas dari beban konflik masa lalu.

Konflik yang terjadi di Pattani lebih banyak membawa dampak negatif dalam sistem pendidikan di Sekolah Songserm Islam Seksa (SSIS) yaitu berkurangnya jam belajar, prestasi belajar siswa menurun, menurunnya kinerja guru, tidak menentunya sistem pendidikan sekolah disebabkan oleh berubah-rubahnya kebijakan pemerintah dalam rangka resolusi konflik, dan sekolah harus libur secara mendadak ketika terjadi konflik.Sedangkan resolusi konflik berdampak positif bagi Sistem Pendidikan Agama Islam di Sekolah Songserm Islam Seksa diantaranya adalah meningkatkan kualitas kinerja guru dalam proses pembelajaran di sekolah agama Islam swasta, Tumbuhnya semangat pendidik dalam proses pembelajaran di sekolah agama Islam,dan terbentuknya budaya belajar yang efektif dan kondusif di sekolah Sekolah Songserm Islam Seksa.

\section{Daftar Pustaka}

Ali, Kettani M. 2005. Minoritas Muslim di Dunia Dewasa Ini. Terj. Zarkowi Soejoeti. Jakarta: PT Raja Grafindo Persada.

Bueto, Usman. 2010. Gerakan Muslim-Melayu di Thailand Selatan 1973-1980 M. (Gerakan Perlawanan Minoritas Terhadap Mayoritas). Skripsi. Fakultas Adab dan Ilmu BudayaUIN Sunan Kalijaga Yogyakarta.

Capakiya, Ahmad Omar. 2002. Politik dan Perjuangan Masyarakat Islam Selatan Thailand 1909-2002. Kuala Lumpur: UKM.

Capakiya, Ahmad Omar. 2002. Politik dna Perjuangan Masyarakat Islam Selatan Thailand 1909-2002. Kuala Lumpur: UKM.

Fathy, Ahmad. 1994. Pengantar Sejarah Patani. Alor Setar: Pustaka Darul Aman

Hasbullah, Moeflich 2003. Asia Tenggara Konsentrasi Baru Kebangkitan Islam. Bandung: Fokus Media.

Ibrahim, Syukri. Tt. Kerajaan Melayu Patani. Kelantan: Majlis Agama Islam Kelantan). 
Machali, Imam. 2013. Peace Education dan Deradikalisasi Agama. Jurnal Pendidikan Islam. Volume 2. Nomor 1: 41-64, doi:10.14421/jpi.2013.21.41-64.

Madami,Usamarn. 2013. Islam di Muang Thai Selatan Inkulturasi Nilainilai Islam dalam Kebudayaan Melayu. Disertasi. Yogyakarta: Program Pacasarjana UIN Sunan Kalijaga.

Mahyeeteh, Abduraheem. 2002. Pendidikan Agama Islam pada Ma'had Darussalam Yala, Thailand. Tesis. Program Pacasarjana Universitas Islam Indonesia Yogyakarta.

Malik, Mohd. Zambari A. 1994. Patani Dalam Tamadun Melayu. Kuala Lumpur: Dewan Bahasa dan Pustaka Kementrian Pendidikan Melaysia.

Nurdi, Herry. 2010. Perjuangan Muslim Patani, Antara Sejarah Penindasan dan Cita-cita Perdamaian di Patani Darussalam. Jakarta: Sabili Publishing

Pitsuwan, Surin. 1989. Islam di Muangthai Nasionalisme Melayu Masyarakat Patani. Terj. Hasan Basri. Jakarta: LP3S.

Saiful, Muzani. 1993. Pembangunan dan Kebangkitan Islam di Asia Tenggara. Jakarta: LP3ES.

Siripachana, Narong. 1975. Kwam Penma Khong Islam le' Dato' Yuttitham. Bangkok: PT. Popit Press.

Siripachana, Narong. 1975. Kwam Penma Khong Islam le’ Dato' Yuttitham. Bangkok: PT. Popit Press.

\section{Website}

http://soreda.oas.psu.ac.th/show detail.php?research id=392. Diakses 07/05/14.

http://bangkokbiznews.com/home/html. Diakses 07/052014. 